\title{
Effects of icariin on the expression of ER, VEGF, and KDR in the endometrial cells of thin endometrium
}

\author{
A.W. Le, L. Shan, Z.H. Wang, X.Y. Dai, T.H. Xiao and R. Zuo \\ Department of Gynecology, Nanshan Affiliated Hospital of Guangdong Medical College, \\ Shenzhen, China
}

Corresponding author: Z.H. Wang

E-mail: leaiwen@126.com

Genet. Mol. Res. 14 (3): 11250-11258 (2015)

Received February 2, 2015

Accepted July 10, 2015

Published September 22, 2015

DOI http://dx.doi.org/10.4238/2015.September.22.19

ABSTRACT. We explored the effects of icariin on the expression of estrogen receptor (ER), vascular endothelial growth factor (VEGF), and kinase insert domain receptor (KDR) in the endometrial cells of the thin endometrium. Primary endometrial cells were obtained and divided into a blank control group, a high-, a middle-, and a low-dose icariin groups, as well as an estrogen treatment group to undergo cellular identification by immunocytochemistry. The expression levels of ER, VEGF, and its receptor were estimated by western blotting. The expression levels of ER, VEGF, and KDR gradually increased from the control group to the estrogen (E2) treatment and icariin treatment groups; the differences were statistically significant. However, the differences were not statistically significant among the different icariin dose groups. The endometrium may be thickened by icariin treatment by increasing the expression levels of ER, VEGF, and KDR in endometrial cells.

Key words: Thin endometrium; Vascular endothelial growth factor; Estrogen receptor 


\section{INTRODUCTION}

A thin uterine endometrium has an endometrial thickness less than that required for a successful pregnancy. Not only does it occur after uterine cavity manipulation and infection (Shufaro et al., 2008), but it is also related to endocrine disorder, aging, and drug induction (Kumbak and Sahin et al., 2009; Le et al., 2013). The pathological and physiological characteristics of a thin endometrium were first described by Miwa et al. (2009) as slow growth of the glandular epithelium, high resistance of the uterine artery blood flow, vascular dysplasia, and low expression of vascular endothelial growth factor (VEGF). Currently, thin endometrium is diagnosed when the endometrial thickness is less than 7-8 mm, as detected by ultrasound during the late follicular phase or after ovulation stimulates the endometrial wall for 6-8 days ( $\mathrm{Ng}$ et al., 2007; Venetis et al., 2009). A thick endometrium is associated with a higher rate of successful pregnancy, live births, and ongoing pregnancy compared with women with thin endometria (Zhang et al., 2005). It is thought that a prerequisite of successful embryo implantation is the thickness of the endometrium: more than $6 \mathrm{~mm}$ and preferably 7-8 mm (Basir et al., 2002; Bodri et al., 2007). Therefore, a thicker endometrium aids a successful pregnancy.

There are various therapeutic approaches towards increasing a thin endometrium, which include regeneration of endometrial cells, improving blood circulation to the endometrium, and enhancing the expression level of growth factors. The treatments mainly focus on medications that target the primary disease by regulating endocrine secretion and improving microcirculation (Gargett and Masuda, 2010; Glujovsky et al., 2010; Zhao et al., 2010; Bodombossou-Djobo et al., 2011; Gleicher et al., 2011; Hu and Yuan, 2011; Nagori et al., 2011; Revel, 2012). The treatment efficacy of icariin on thin endometrium has been approved based on the results from clinical trials. The thickness of an endometrium is regulated by several factors, one of which is estrogen. Estrogen exerts its biological effects by binding to the estrogen receptor $(E R)$ to promote both cyclical endometrial vascular reconstruction and endometrial repair. VEGF is also indispensable for endometrium growth and functions by binding to the receptor kinase insert domain receptor (KDR). Our previous studies have indicated that patients with thin endometria have decreased ER, VEGF, and KDR expression levels compared with the normal endometrium. Therefore, in the current study, the expression levels of ER, VEGF, and KDR in response to icariin treatment were measured with the objective of exploring the mechanism by which icariin treatment affects the endometrium.

\section{MATERIAL AND METHODS}

\section{Material}

Human endometrial tissue was obtained from patients with irregular menstruation undergoing diagnostic uterine curettage between August 2014 and December 2014. Patients average age was $32.2 \pm 4.6$ years (with ages ranging from 23 to 41 years), and had previously had regular menstruation. The patients enrolled had no history of hormone deficiency 3 months prior to undergoing diagnostic uterine curettage. This study was approved by the Nanshan Affiliated Hospital of Guangdong Medical College, and written informed consent was obtained from every participant. Endometrial tissue (6-8 g) was obtained under sterile conditions and stored in sterile bottles, then transferred in an ice bath within $30 \mathrm{~min}$ to the laboratory for tissue separation and cell culture. Partial tissues were taken out and fixed using 10\% formaldehyde for pathological study, and the biological analysis was performed subsequent to cell culture if there were no abnormal pathological findings. 


\section{Endometrial cell separation and culture}

The tissue was mixed with $0.1 \%$ collagenase at a volume ratio of $1: 1$ and $0.25 \%$ trypsinethylenediaminetetraacetic acid was added at a ratio of $5: 1$. The tissue was digested for 60 min with slight shaking every $15 \mathrm{~min}$. Complete medium was then added to terminate the digestive reaction when flocculent precipitates were observed in the digestion solution. Stromal cells were isolated by differential centrifugation as follows: the digested cell suspension was centrifuged for 3 min at $500 \mathrm{rpm}$, the supernatants were collected, and further centrifuged for $10 \mathrm{~min}$ at $1200 \mathrm{rpm}$. The precipitates were stromal cells and were cultured with complete medium at a density of $1 \times 10^{6} / \mathrm{mL}$. Epithelial cells were isolated by digestion as follows: the digested cell suspension was centrifuged for $3 \mathrm{~min}$ at $500 \mathrm{rpm}$ and the precipitate was collected and washed with serum-free Dulbecco's modified Eagle's medium (DMEM)/F12 culture medium followed by 800 rpm centrifugation for 5 $\min$. Trypsin-ethylenediaminetetraacetic acid $(0.25 \%)$ was added to the precipitates at a volume ratio of $5: 1$ and the mixture was incubated in $\mathrm{CO}_{2}$ at $37^{\circ} \mathrm{C}$ for $10 \mathrm{~min}$. The secondary digested products were centrifuged again at $800 \mathrm{rpm}$ for $5 \mathrm{~min}$ and the precipitates were re-suspended with complete culture medium at a cell density of $1 \times 10^{6} / \mathrm{mL}$. Both stromal and epithelial cells adhered to the bottom of the petri dish after culture for $24 \mathrm{~h}$.

\section{Experimental groups}

Blank control group: the cells were cultured in serum-free DMEM with high glucose content.

High-dose icariin group: the cells were cultured in DMEM with high glucose content and $15 \%$ serum containing high-dose icariin.

Middle-dose icariin group: the cells were cultured in DMEM with high glucose content and $15 \%$ serum containing middle-dose icariin.

Low-dose icariin group: the cells were cultured in DMEM with high glucose content and $15 \%$ serum containing low-dose icariin.

Estrogen treatment group: the cells were cultured in DMEM with high glucose content and $15 \%$ serum containing estrogen.

Serum-free culture medium was used as a blank control and estrogen treatment was used as a positive control.

The high, middle, and low doses of icariin were 20,15 , and $10 \mu \mathrm{M}$, respectively. The concentration of estrogen (E2) was $10^{-6} \mu \mathrm{M}$.

\section{Chemical staining to identify stromal and epithelial cells}

Stromal and epithelial cells were grown on glass slides, and were stained with antibodies against vimentin and cytokeratin-19 (CK-19), respectively. The first antibodies were mouse antihuman vimentin monoclonal antibodies and rabbit anti-human CK-19 monoclonal antibodies, and both were utilized at a dilution of 1:20. The secondary antibodies were biotinylated goat anti-mouse or rabbit IgG. Astreptavidin binding kit was used for antibody-antigen complex detection, and the staining reaction was performed according to the manufacturer instructions. PSR was used to substitute first antibodies as the negative control.

\section{Protein expression detection}

Semi-quantitative western blotting was used for protein expression detection (Green 
and Sambrook, 2012). The western blotting membrane was analyzed using the Gel Scan image analysis system; the band intensity of each lane was quantitatively measured and normalized by the intensity of the blank area.

\section{Statistical analysis}

The SPSS 16.0 software was used for statistical analyses. The measurements are reported as means $\pm S D$ and were compared by variance analysis. The significance of betweengroup differences was tested using analysis of variance or chi-square tests. Values of $P<0.05$ were considered to be statistically significant.

\section{RESULTS}

\section{Endometrial cells}

The differential centrifugation-isolated endometrial cells adhered to the bottom of the Petri dish after culturing for 2 days. The cells had small and round nuclei with relatively less cytoplasm and shirt-shaped boundaries (Figure 1). The cells started to turn into spindle shapes with strong refraction; the nuclei were located in the middle of the cells and also turned into spindle shapes. All the cells were arranged in a parallel format (Figure 2). Both CK-19-positive cells and vimentinpositive cells appeared brownish-yellow in color (Figures 3 and 4).

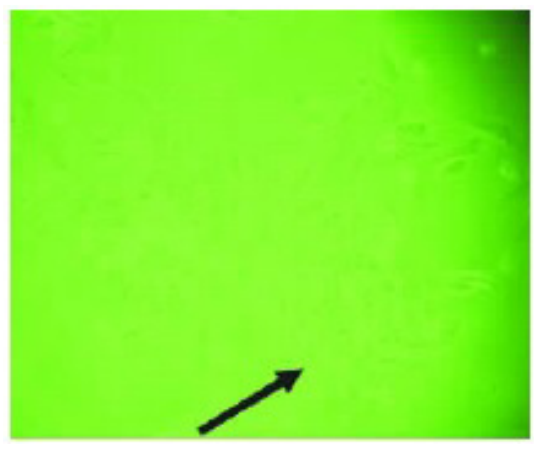

Figure 1. Endometrial epithelial cells (100X).

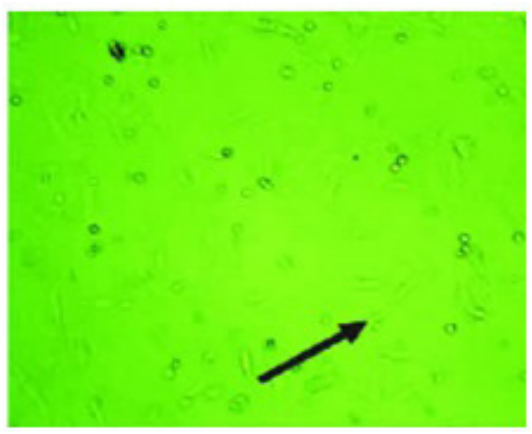

Figure 2. Endometrial stromal cells (100X). 


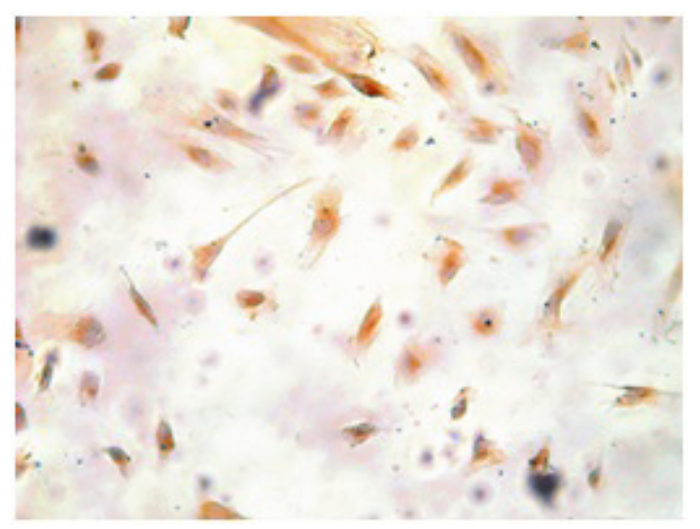

Figure 3. Endometrial epithelial cells stained with anti-CK-19 antibody. Immunohistochemistry staining image (100X).

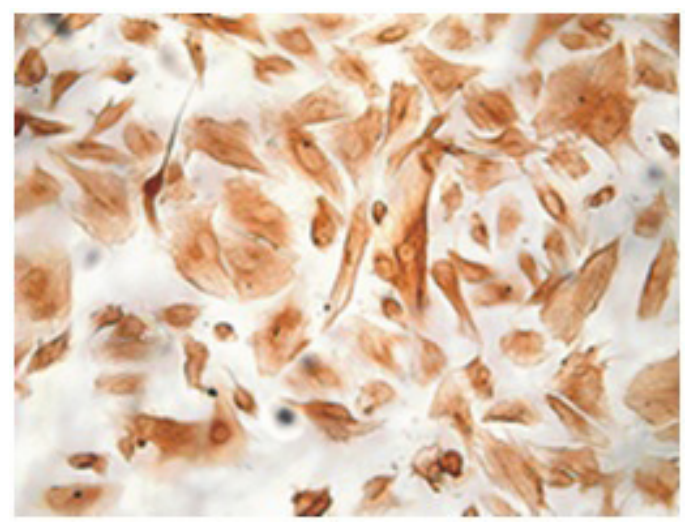

Figure 4. Endometrial stromal cells stained with anti-vimentin antibody. Immunohistochemistry staining image (100X).

\section{Protein electrophoresis}

As shown in Figures 5 to 8 and Tables 1 to 4 , there was no significant difference relative to glyceraldehyde 3-phosphate dehydrogenase expression among the groups. The expression levels of ER, VEGF, and KDR were gradually elevated from the control group to the E2 treatment group and icariin treatment groups, respectively; the differences were statistically significant. The differences were not statistically significant among the different doses in the icariin groups.

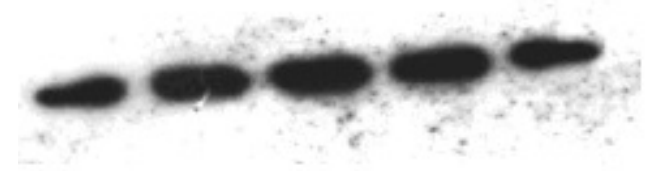

Figure 5. Expression of internal control glyceraldehyde 3-phosphate dehydrogenase (GAPDH). Control; E2; low-dose; middle-dose; high-dose. 


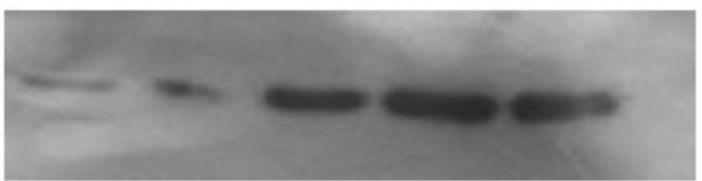

Figure 6. Expression of vascular endothelial growth factor (VEGF). Control; E2; low-dose; middle-dose; high-dose.

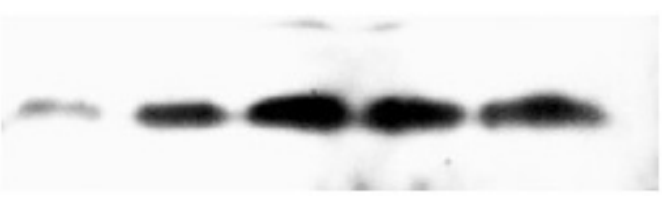

Figure 7. Expression of kinase insert domain receptor (KDR). Control; E2; low-dose; middle-dose; high-dose.

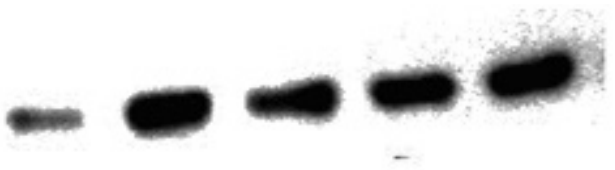

Figure 8. Expression of estrogen receptor (ER). Control; low-dose; E2; middle-dose; high-dose.

Table 1. Comparison of Glyceraldehyde 3-phosphate dehydrogenase (GAPDH) protein expression.

\begin{tabular}{lll}
\hline Group & GAPDH & $P$ \\
\hline Control & $620.9 \pm 216.5$ \\
E2 & $657.3 \pm 234.2$ \\
Low & $662.5 \pm 216.8$ \\
Middle & $638.1 \pm 207.7$ \\
High & $618.6 \pm 193.9$ \\
\hline
\end{tabular}

Table 2. Comparison of Vascular endothelial growth factor (VEGF) protein expression.

\begin{tabular}{lll}
\hline Group & VEGF & $P$ \\
\hline Control & $239.1 \pm 88.9$ \\
E2 & $361.2 \pm 87.3$ \\
Low & $443.6 \pm 115.2$ \\
Middle & $465.2 \pm 126.3$ \\
High & $457.5 \pm 129.5$ \\
\hline
\end{tabular}

Table 3. Comparison of Kinase insert domain receptor (KDR) protein expression.

\begin{tabular}{ll}
\hline Group & KDR \\
\hline Control & $229.3 \pm 80.1$ \\
E2 & $395.3 \pm 89.5$ \\
Low & $626.5 \pm 198.3$ \\
Middle & $598.4 \pm 178.9$ \\
High & $565.3 \pm 168.8$ \\
\hline
\end{tabular}

Genetics and Molecular Research 14 (3): 11250-11258 (2015) 
Table 4. Comparison of Estrogen receptor (ER) protein expression.

\begin{tabular}{llc}
\hline Group & ER & P \\
\hline Control & $238.2 \pm 89.9$ & 0.037 \\
E2 & $420.3 \pm 92.6$ & \\
Low & $678.6 \pm 199.8$ & \\
Middle & $628.8 \pm 183.6$ & \\
High & $637.5 \pm 197.5$ & \\
\hline
\end{tabular}

\section{DISCUSSION}

The successful implantation of an embryo is dependent on the quality of the embryo and the endometrial receptivity. An endometrial thickness greater than $7 \mathrm{~mm}$ is the prerequisite for successful pregnancy, and 2/3 implantation failures are associated with poor endometrial receptivity (Achache and Revel, 2006). Good hemoperfusion of the endometrial tissue usually indicates fair endometrial receptivity and reflects a satisfactory microenvironment for implantation, which is critical for successful implantation of the embryo (Kim et al., 2010; Wang et al., 2010).

Estrogen and progesterone exert their biological functions through binding to their specific receptors in the endometrium, and the expression levels of these receptors are periodically changed in accordance with the normal menstrual cycle of healthy women (Bulun et al., 2012; Henriet et al., 2012).

Endometrial angiogenesis is regulated by multiple factors, and VEGF is one of those regulatory factors with a strong effect and high specificity. VEGF is a specific mitogen for vascular endothelial cells, mainly through tight binding to receptor FIt-1 and KDR on endothelial cells. VEGF is able to induce hyperplasia in endothelial cells, form capillary loops, increase microvascular permeability, and stimulate production of the cellular matrix, so as to promote neovascularization (Kaczmarek et al., 2007). The proliferation, transformation, and structure formation of the vascular endothelium are stimulated by VEGF autocrine or paracrine activities, which promote differentiation of blood vessels and maintain vascular permeability.

Estrogen enhances mRNA levels of several growth factors in the mouse uterus, and in vivo animal studies have reinforced the idea of the angiogenesis effect of recombinant bovine fibroblast growth factor. Therefore, a synergistic effect of ER and growth factors on angiogenesis has been postulated. However, this mechanism has not been fully elucidated (Hyder et al., 2007). Moreover, it has been reported that KDR expression in the endometrium could be increased by estrogen through the VEGF paracrine pathway (Applanat et al., 2008). In the current study, the expression levels of ER, VEGF, and KDR were increased in the icariin and estrogen treatment groups compared with the control group, which indicates that both icariin and estrogen can enhance endometrial proliferation and repair through upregulating expression of ER, VEGF, and KDR. However, a dose-dependent increase of ER, VEGF, and KDR expression was not observed in the study, which might be ascribed to the limited range of icariin doses and the relatively small size of the samples.

It was demonstrated by Hyder et al. (2000) that ER might be one of the major regulatory factors for expression of VEGF; these authors further showed that two estrogen-response elements of the ER gene were similar to those of VEGF with high homologyat the $5^{\prime}$ and $3^{\prime}$ untranslated regions of the VEGF gene. These two elements can specifically bind to ER $\alpha$ and ER $\beta$. In addition, it was found by Buteau-Lozano et al. (2002) that the VEGF promoter from +54 to +749 is similar to the estrogen response element with $80 \%$ homology, and also binds to ER. Furthermore, the 
VEGF expression regulation through ERa/Sp1and ERa/Sp3 binding to the proximal and distal GC/GT sequence observed by Higgins et al. (2008), the association between ER and GC-rich elements of Sp1/Sp3 in the EVGF promoter discovered by Chennazhi and Nayak (2009), and the positive correlation between expression of ER and VEGF (as well as the variants of ER increasing expression of VEFG) revealed by Koduri et al. (2006), are all consistent with the findings of this study.

VEGF is an important angiogenic factor that promotes neovascularization by increasing vascular permeability, altering the gene expression profile in vascular endothelial cells, and promoting mitosis of vascular endothelial cells (Claesson-Welsh, 2012).

In summary, the effect of icariin on the thin endometrium was demonstrated in our assay by the increased expression of ER, VEGF, and KDR, resulting in enhanced endometrial angiogenesis and endometrial hyperplasia. Other regulatory mechanisms may also be involved, which warrant further investigation.

\title{
Conflicts of interest
}

The authors declare no conflict of interest.

\section{ACKNOWLEDGMENTS}

\author{
Research supported by a grant from the Research Fund of the Shen Zhen City Technology \\ Creative Committee (\#JCYJ2014041109115144).
}

\section{REFERENCES}

Achache $\mathrm{H}$ and Revel A (2006). Endometrial receptivity markers, the journey to successful embryo implantation. Hum. Reprod. Update 12: 731-746.

Applanat MP, Buteau-Lozano H, Herve MA and Corpet A (2008). Vascular endothelial growth factor is a target gene for estrogen receptor and contributes to breast cancer progression. Adv. Exp. Med. Biol. 617: 437-444.

Basir GS, O WS, So WW and Ng EH (2002). Evaluation of cycle-to-cycle variation of endometrial responsiveness using transvaginal sonography in women undergoing assisted reproduction. Ultrasound Obstet. Gynecol. 19: 484-489.

Bodombossou-Djobo MM, Zheng C, Chen S and Yang D (2011). Neuromuscular electrical stimulation and biofeedback therapy may improve endometrial growth for patients with thin endometrium during frozen-thawed embryo transfer: a preliminary report. Reprod. Biol. Endocrinol. 9: 122.

Bodri D, Colodron M, Vidal R, Galindo A, et al. (2007). Prognostic factors in oocyte donation: an analysis through egg-sharing recipient pairs showing a discordant outcome. Fertil. Steril. 88: 1548-1553.

Bulun SE, Monsavais D, Pavone ME, Dyson M, et al. (2012). Role of estrogen receptor- $\beta$ in endometriosis. Semin. Reprod. Med. 30: 39-45

Buteau-Lozano H, Ancelin M, Lardeux B, Milanini J, et al. (2002). Transcriptional regulation of vascular endothelial growth factor by estradiol and tamoxifen in breast cancer cells: a complex interplay between estrogen receptors alpha and beta. Cancer Res. 62: 4977-4984.

Chennazhi KP and Nayak NR (2009). Regulation of angiogenesis in the primate endometrium: vascular endothelial growth factor. Semin. Reprod. Med. 27: 80-89.

Claesson-Welsh L (2012). Blood vessels as targets in tumor therapy. Ups. J. Med. Sci. 117: 178-186.

Gargett CE and Masuda H (2010). Adult stem cells in the endometrium. Mol. Hum. Reprod. 16: 818-834.

Gleicher N, Vidali A and Barad DH (2011). Successful treatment of unresponsive thin endometrium. Fertil. Steril. $95: 2123$. e13-e17.

Glujovsky D, Pesce R, Fiszbajn G, Sueldo C, et al. (2010). Endometrial preparation for women undergoing embryo transfer with frozen embryos or embryos derived from donor oocytes. Cochrane Database Syst. Rev. 1: CD006359.

Green MR and Sambrook J (2012). Molecular Cloning: A Laboratory Manual. 4th edn. Cold Spring Harbor Laboratory Press, 
New York.

Henriet P, Gaide Chevronnay HP and Marbaix E (2012). The endocrine and paracrine control of menstruation. Mol. Cell Endocrinol. 358: 197-207.

Higgins KJ, Liu S, Abdelrahim M, Vanderlaag K, et al. (2008). Vascular endothelial growth factor receptor-2 expression is downregulated by 17 beta-estradiol in MCF-7 breast cancer cells by estrogen receptor alpha/Sp proteins. Mol. Endocrinol. 22: 388-402.

Hu J and Yuan R (2011). Decreased expression of c-kit and telomerase in a rat model of chronic endometrial ischemia. Med. Sci. Monit. 17: BR103-BR109.

Hyder SM, Nawaz Z, Chiappetta C and Stancel GM (2000). Identification of functional estrogen response elements in the gene coding for the potent angiogenic factor vascular endothelial growth factor. Cancer Res. 60: 3183-3190.

Kaczmarek MM, Kowalczyk AE, Waclawik A, Schams D, et al. (2007). Expression of vascular endothelial growth factor and its receptors in the porcine corpus luteum during the estrous cycle and early pregnancy. Mol. Reprod. Dev. 74: 730-739.

Kim A, Han JE, Yoon TK, Lyu SW, et al. (2010). Relationship between endometrial and subendometrial blood flow measured by three-dimensional power Doppler ultrasound and pregnancy after intrauterine insemination. Fertil. Steril. 94: 747-752.

Koduri S, Goldhar AS and Vonderhaar BK (2006). Activation of vascular endothelial growth factor (VEGF) by the ER-alpha variant, ERDelta3. Breast Cancer Res. Treat. 95: 37-43.

Kumbak B and Sahin $L$ (2009). Woman age and morphologic pattern should be taken into consideration while talking about "thin" endometrium. Fertil. Steril. 92: e38.

Le AW, Wang ZH, Yuan R, Shan LL, et al. (2013). Association of the estrogen receptor- $\beta$ gene Rsal and Alul polymorphisms with human idiopathic thin endometrium. Genet. Mol. Res. 12: 5978-5985.

Miwa I, Tamura H, Takasaki A, Yamagata Y, et al. (2009). Pathophysiologic features of "thin" endometrium. Fertil. Steril. 91: 998-1004.

Nagori CB, Panchal SY and Patel H (2011). Endometrial regeneration using autologous adult stem cells followed by conception by in vitro fertilization in a patient of severe Asherman's syndrome. J. Hum. Reprod. Sci. 1: 43-48.

$\mathrm{Ng} \mathrm{EH}$, Chan CC, Tang OS, Yeung WS, et al. (2007). The role of endometrial blood flow measured by three-dimensional power Doppler ultrasound in the prediction of pregnancy during in vitro fertilization treatment. Eur. J. Obstet. Gynecol. Reprod. Biol. 135: 8-16.

Revel A (2012). Defective endometrial receptivity. Fertil. Steril. 97: 1028-1032.

Shufaro Y, Simon A, Laufer N and Fatum M (2008). Thin unresponsive endometrium - a possible complication of surgical curettage compromising ART outcome. J. Assist. Reprod. Genet. 25: 421-425.

Venetis CA, Kolibianakis EM, Tarlatzi TB and Tarlatzis BC (2009). Benefits of luteinizing hormone activity in ovarian stimulation for IVF. Reprod. Biomed. Online 18: 31-36.

Wang L, Qiao J, Li R, Zhen X, et al. (2010). Role of endometrial blood flow assessment with color Doppler energy in predicting pregnancy outcome of IVF-ET cycles. Reprod. Biol. Endocrinol. 8: 122.

Zhang X, Chen CH, Confino E, Barnes R, et al. (2005). Increased endometrial thickness is associated with improved treatment outcome for selected patients undergoing in vitro fertilization-embryo transfer. Fertil. Steril. 83: 336-340.

Zhao M, Chang C, Liu Z, Chen LM, et al. (2010). Treatment with low-dose aspirin increased the level LIF and integrin $\beta 3$ expression in mice during the implantation window. Placenta 31: 1101-1105. 